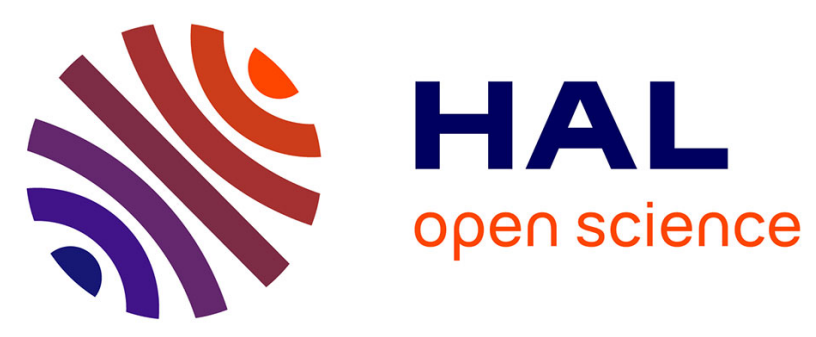

\title{
Comparison of 10 efficient protocols for photodynamic therapy of actinic keratosis: How relevant are effective light dose and local damage in predicting the complete response rate at 3 months?
}

Anne-Sophie Vignion-Dewalle, Grégory Baert, Elise Thecua, Fabienne Lecomte, Claire Vicentini, Henry Abi-Rached, Laurent Mortier, Serge Mordon

\section{To cite this version:}

Anne-Sophie Vignion-Dewalle, Grégory Baert, Elise Thecua, Fabienne Lecomte, Claire Vicentini, et al. Comparison of 10 efficient protocols for photodynamic therapy of actinic keratosis: How relevant are effective light dose and local damage in predicting the complete response rate at 3 months?. Lasers in Surgery and Medicine, 2018, 10.1002/lsm.22827 . hal-01770441

\section{HAL Id: hal-01770441 \\ https://hal.science/hal-01770441}

Submitted on 10 Jan 2019

HAL is a multi-disciplinary open access archive for the deposit and dissemination of scientific research documents, whether they are published or not. The documents may come from teaching and research institutions in France or abroad, or from public or private research centers.
L'archive ouverte pluridisciplinaire HAL, est destinée au dépôt et à la diffusion de documents scientifiques de niveau recherche, publiés ou non, émanant des établissements d'enseignement et de recherche français ou étrangers, des laboratoires publics ou privés. 


\title{
Comparison of ten efficient protocols for photodynamic therapy of actinic keratosis: How relevant are effective light dose and local damage in predicting the complete response rate at three months?
}

Anne-Sophie Vignion-Dewalle ${ }^{1}$, Gregory Baert ${ }^{1}$, Elise Thecua ${ }^{1}$, Fabienne Lecomte ${ }^{1}$, Claire Vicentini $^{1,2}$, Henry Abi-Rached ${ }^{1,2}$, Laurent Mortier ${ }^{1,2}$ and Serge Mordon ${ }^{1}$

\author{
${ }^{1}$ Univ. Lille, INSERM, CHU Lille, U1189 - ONCO-THAI - Image Assisted Laser Therapy \\ for Oncology, F-59000 Lille, France \\ ${ }^{2}$ Department of Dermatology, CHU Lille, F-59000 Lille, France
}

Corresponding author: Anne-Sophie Vignion-Dewalle

\author{
INSERM U1189 ONCO-THAI, \\ 1, avenue Oscar Lambret, \\ F-59037 LILLE Cedex, \\ France \\ E-mail: anne-sophie.vignion@inserm.fr
}

\begin{abstract}
Background: Topical photodynamic therapy is an established treatment modality for various dermatological conditions, including actinic keratosis. In Europe, the approved protocols for photodynamic therapy of actinic keratosis involve irradiation with either an Aktilite CL 128 lamp or daylight, whereas irradiation with the Blu-U illuminator is approved in the United States. Many other protocols using irradiation by a variety of light sources are also clinically efficient.
\end{abstract}

Objectives: This paper aims to compare ten different protocols with clinically proven efficacy for photodynamic therapy of actinic keratosis and the available spectral irradiance of the light source. Effective irradiance, effective light dose and local damage are compared. We also investigate whether there is an association between the complete response rate at three months and the effective light dose or local damage.

Methods: The effective irradiance, also referred to as protoporphyrin IX-weighted irradiance, is obtained by integrating the spectral irradiance weighted by the normalized absorption spectrum of protoporphyrin IX over the wavelength. Integrating the effective irradiance over 
the irradiation time yields the effective light dose, which is also known as the protoporphyrin IX-weighted light dose. Local damage, defined as the total cumulative singlet oxygen molecules produced during treatment, is estimated using mathematical modeling of the photodynamic therapy process. This modeling is based on an iterative procedure taking into account the spatial and temporal variations in the protoporphyrin IX absorption spectrum during treatment.

Results: The protocol for daylight photodynamic therapy on a clear sunny day, the protocol for daylight photodynamic therapy on an overcast day, the photodynamic therapy protocol for a white LED lamp for operating rooms and the photodynamic therapy protocol for the Blu-U illuminator perform better than the six other protocols - all involving red light illumination in terms of both effective light dose and local damage. However, no association between the complete response rate at three months and the effective light dose or local damage was found.

Conclusions: Protocols that achieve high complete response rates at three months and low pain scores should be preferred regardless of the effective light dose and local damage.

Keywords: Photodynamic therapy, actinic keratosis, protocols with clinically proven efficacy, protocols with available spectral irradiance for the light source, effective irradiance, effective light dose, local damage, complete response rate at three months. 


\section{Introduction}

Photodynamic therapy (PDT), which is an established modality for the treatment of a variety of skin conditions, including skin cancers, combines the use of a light of an appropriate wavelength, a nontoxic photosensitizer, and sufficient molecular oxygen to generate reactive oxygen species and destroy target cells [1]. Over the last 15 years, PDT using 5aminolevulinic acid (ALA) (ALA-PDT) and PDT using 5-aminolevulinic acid methyl ester (MAL) (MAL-PDT) have been extensively investigated, particularly for the treatment of actinic keratosis (AK) [2-6]. Topical administration of ALA or MAL leads, after the incubation time, to the selective accumulation of the endogenous photosensitizer protoporphyrin IX (PpIX) in the $\mathrm{AK}$ cells, and subsequent light irradiation induces photochemical reactions leading to cell death.

A variety of ALA- and MAL-PDT protocols have been proposed for the treatment of AK [26]. In this paper, we propose a comparison of ten different ALA- and MAL-PDT protocols with clinically proven efficacy for PDT of AK and available spectral data for the light source. The comparison is performed in terms of effective irradiance, effective light dose and local damage. The effective irradiance, also referred to as the PpIX-weighted irradiance, is obtained by integrating the spectral irradiance of the light source weighted (i.e., multiplied for each wavelength) by the normalized absorption spectrum of PpIX over the wavelength. Integrating this effective irradiance over the irradiation time gives the effective light dose, also known as the PpIX-weighted light dose. Local damage, which is defined as the estimate of the total cumulative singlet oxygen molecules produced during treatment, is computed by mathematical modeling of PDT of AK, which we have published previously [7-9]. Based on an iterative procedure, this modeling takes into account the spatial and temporal variations in the absorption spectrum of PpIX during treatment.

Furthermore, the complete response rates at three months, which are reported in the literature for nine of the ten investigated protocols, are compared to the effective light doses and local damage. This comparison aims to investigate whether there is an association between the complete response rate at three months and the effective light dose or local damage. 
The ten ALA- and MAL-PDT protocols investigated in this study are described in the Materials and Methods section. This section also includes a description of the three comparative metrics. The protocols are then evaluated and compared in the Results section, which also addresses the relationships of the complete response rate at three months with the effective light dose and with local damage. Finally, some discussions and conclusions are drawn in the Discussion section.

\section{Materials and Methods}

\section{A. ALA- and MAL-PDT protocols for AK treatment}

Ten different ALA- and MAL-PDT protocols are investigated in this study. For each protocol, a description specifying the incubation time, light source, irradiation time, removal of excess cream, and any potential additional protocol information is given. All protocol information was collected from the studies establishing the clinical efficacy of the protocols.

The order in which the protocols appear is determined by the technology of the involved light sources.

Table 1 summarizes the abovementioned information for the ten ALA- and MAL-PDT protocols investigated in this study (columns 2 to 6 ) as well as the complete response rates at three months (column 7) and the pain scores during irradiation (column 8). Only the complete response rates and the pain scores achieved in AK after one PDT session are considered in this study.

\section{1. $\quad$ Daylight}

Since the early work of Wiegell et al. 2008 [10], many studies on daylight PDT for the treatment of AK have been published [6,11-22]. Application of a chemical sunscreen to the treatment area to prevent sunburn, followed by a maximum of 30 minutes of MAL incubation and no excess cream removal before exposure to daylight for two hours, was adopted as the so-called international consensus protocol for daylight PDT from a European consensus in 2012 [13]. In our study, we investigated the performance of the international consensus 
protocol for daylight PDT for an incubation time of 30 minutes. This choice was based on a randomized clinical trial that demonstrated that this protocol is as effective as but less painful than the conventional protocol for Aktilite CL 128 PDT (described in Paragraph II.A.2.a.iii, the conventional protocol for Aktilite CL 128 PDT is commonly used for standard PDT of $\mathrm{AK}$ in Europe) [16]. Moreover, as this randomized clinical trial was conducted under all weather conditions except rain and cold, two spectral irradiances for daylight are used in this study. The first corresponds to a clear sunny day at 10h28 (orange yellow curve in Figure 1) and thus is used to set the protocol for daylight PDT on a clear sunny day, whereas the second corresponds to an overcast day at 13h45 (dark gray curve in Figure 1) and defines the protocol for daylight PDT on an overcast day. The two spectral irradiances recorded between April and July 2014 in Dublin, Ireland, were kindly provided by the authors of O'Gorman et al. [21].

\section{2. $\quad$ Artificial light sources}

\section{a) Incoherent light sources}

Three main technologies for turning electricity into incoherent light - incandescent bulbs, gas discharge lamps and light-emitting diodes - have been investigated as light sources for PDT.

\section{i. Incandescent light bulb}

Since the advent of PDT for dermatology, incandescent bulbs, particularly halogen bulbs, have been employed as light sources. In this study, we have investigated a protocol for the broadband halogen CureLight 01 lamp (Photocure ASA, Oslo, Norway). This protocol involves a three-hour MAL incubation followed by removal of excess cream before irradiation with a light dose of $75 \mathrm{~J} / \mathrm{cm}^{2}$ and has been proven clinically effective for $\mathrm{AK}$, based on reported complete response rates at three months of 68.7 to $91 \%$ (after one or two treatment sessions) [23-26]. The spectral irradiance for the CureLight 01 lamp used in this study is depicted in Figure 1 (maroon curve). This spectral irradiance is obtained by weighting the CureLight 01 lamp spectral irradiance provided in relative units by the authors of [27] to yield an irradiance of $154 \mathrm{~mW} / \mathrm{cm}^{2}$. With this irradiance, which is the mean irradiance measured for the CureLight 01 lamp in [23], the above light dose of $75 \mathrm{~J} / \mathrm{cm}^{2}$ is achieved using an irradiation time of 487 seconds. 


\section{ii. Gas discharge lamp}

Gas-discharge lamps include many categories, such as metal halide lamps, xenon arc lamps, fluorescent lamps, mercury lamps, and sodium lamps. In this study, we investigate two protocols involving irradiation with commercial gas discharge lamps.

The first protocol is the manufacturer-recommended protocol for the Waldmann PDT 1200L (Waldmann Medizintechnik, VS-Schwennigen, Germany) [28], which is a metal halide lamp widely investigated for PDT of AK [28-35]. This protocol, which involves an incubation for four hours with ALA cream and removal of excess cream before irradiation at $160 \mathrm{~mW} / \mathrm{cm}^{2}$ for 625 seconds (the irradiation time required to achieve the recommended light dose of 100 $\mathrm{J} / \mathrm{cm}^{2}$ ), has been demonstrated to be clinically effective for ALA-PDT of AK [28]. The spectral irradiance used in this study for the Waldmann PDT 1200L was derived by weighting the relative spectral irradiance provided by the manufacturer to obtain an irradiance of 160 $\mathrm{mW} / \mathrm{cm}^{2}$. This spectral irradiance is depicted in sienna in Figure 1.

The second protocol, which is the most commonly used approved protocol in the United States, involves irradiation with the widely available Blu-U illuminator (DUSA, Wilmington, Massachusetts, USA) [36-39]. The Blu-U protocol, which involves an ALA incubation time of 14 hours (within a recommended range of 14 to 18 hours) and excess cream removal before irradiation with a light dose of $10 \mathrm{~J} / \mathrm{cm}^{2}$ administered in $1000 \mathrm{~s}$ (resulting in an irradiance of $10 \mathrm{~mW} / \mathrm{cm}^{2}$ ), has been demonstrated to be an effective therapy for PDT of AK in various clinical studies [36-39]. The spectral irradiance for the Blu-U that we use to evaluate this protocol is shown in blue in Figure 1. This spectral irradiance is computed by weighting the spectral irradiance extracted from some DUSA Pharmaceuticals files (See: https://www.physiciansofficeresource.com/por-resources/pdf/2099-8132-learn-more.pdf) to achieve an irradiance of $10 \mathrm{~mW} / \mathrm{cm}^{2}$.

\section{iii. LED lamp}

In early 2000, developments in LED technology enabled the introduction of LED lamps as light sources in dermatological PDT. In this study, four protocols involving irradiation with LED lamps are evaluated. The first three are commercial solutions for dermatological PDT. 
The first protocol involves irradiation with an Aktilite CL 128 lamp (Galderma SA, Lausanne, Switzerland), which is the most widely used LED lamp for topical PDT in Europe [16,26,4046]. In this paper, we evaluate the so-called conventional protocol for Aktilite CL 128 PDT (incubation with MAL cream: three hours; excess cream removal; light dose: $37 \mathrm{~J} / \mathrm{cm}^{2}$ ). This protocol, which is clinically proven to be effective for the treatment of AK [10,16,40-44], is approved and widely used in Europe. To evaluate this protocol, we use the spectral irradiance measured at a distance of $8 \mathrm{~cm}$ from the Aktilite CL 128 lamp by O'Gorman et al. [21] (dark orange curve in Figure 1).

The second protocol is the manufacturer-recommended protocol for the Omnilux PDT TM (Photo Therapeutics Inc., Carlsbad, California) [28]. This protocol, which has been proven clinically efficient for PDT of AK [28], involves a four-hour ALA incubation, excess cream removal, and irradiation with a light dose of $40 \mathrm{~J} / \mathrm{cm}^{2}$ [28]. The spectral irradiance used in this paper (orange red curve in Figure 1) was recorded at $3.5 \mathrm{~cm}$ from the front of the Omnilux PDT тм by O'Gorman et al. [21].

The third protocol employs the Ambulight PDT тм device developed by Ambicare Health Ltd (St Andrews, UK) as the light source [47-49]. This protocol, which has been reported to be efficient with similar 1-year clearance rates as the conventional protocol for Aktilite CL 128 PDT [49], has the following characteristics: three hours of incubation with MAL, no excess cream removal, and $75 \mathrm{~J} / \mathrm{cm}^{2}$ irradiation at an irradiance of $7 \mathrm{~mW} / \mathrm{cm}^{2}$. The spectral irradiance for the Ambulight PDT TM that we use to evaluate this protocol is extracted from [49] (salmon curve in Figure 1).

The fourth protocol involves irradiation with a white LED lamp for operating rooms [21]. Replacing daylight irradiation with irradiation with this white LED lamp in the international consensus protocol for daylight PDT has been proven to achieve similar efficiency [21]. Note that the resulting protocol (incubation with MAL cream: 30 minutes; no excess cream removal; irradiation: two hours) does not require the application of a chemical sunscreen. The spectral irradiance for the white LED lamp for operating rooms provided by O'Gorman et al [21] is represented in light gray in Figure 1.

b) Coherent light sources

i. Laser 
Various studies report the use of lasers as a light source for PDT of AK. In this study, only one protocol involving irradiation with a laser is investigated. This protocol, which includes incubation for 30 minutes with MAL cream and no excess cream removal, involves fractionated irradiation (6.7 milliseconds light, 13.4 milliseconds dark) with an irradiance of 4 $\mathrm{mW} / \mathrm{cm}^{2}$ for 9000 seconds, resulting in a light dose of $12 \mathrm{~J} / \mathrm{cm}^{2}$ [50]. Based on the preliminary results of a clinical trial with Principal Investigator Pr. Laurent Mortier, one of the authors of this study (ClinicalTrials.gov Identifier: NCT03076892) (http://www.phosistos.com/), this protocol, which is called the PDT protocol for the PHOSISTOS device, has been proven to be not inferior in terms of the complete response rate to the conventional protocol for Aktilite CL 128 PDT [51,52]. The spectral irradiance that we measured for the PHOS-ISTOS device is shown in red in Figure 1.

\section{B. Comparative metrics}

For each of the protocols investigated in this study, several metrics are computed from the protocol information:

- The irradiance, which is obtained by integration over the wavelength of the spectral irradiance;

- The light dose, which is the irradiance integrated over the irradiation time;

- The effective irradiance, which is obtained by integration over the wavelength of the spectral irradiance weighted by the normalized absorption spectrum of PpIX;

- The effective light dose, which is the effective irradiance integrated over the irradiation time;

- The local damage, which is an estimate of the number of singlet oxygen molecules generated during treatment in a $5 \mu \mathrm{m} \times 5 \mu \mathrm{m} \times 5 \mu \mathrm{m}$ volume located at a depth of $100 \mu \mathrm{m}$ in $\mathrm{AK}$.

The irradiance and the light dose, which are sometimes specified when defining the protocol (Table 1), only allow the quantification of the electromagnetic radiation emitted by the involved light source without any consideration of the protocol other than the spectral irradiance and the irradiation time. Regarding the effective irradiance and the effective light dose, an additional consideration for the protocol is the normalized absorption spectrum of PpIX; this is achieved by weighting the spectral irradiance by the normalized absorption 
spectrum of PpIX before integration over the wavelength. This weighting takes into account the varying efficiency of the light source in photoactivating PpIX depending on the wavelength: the higher the PpIX absorption coefficient, the greater the number of photons absorbed and therefore the greater the number of PpIX molecules promoted to the excited state. The effective irradiance therefore indicates the overall efficiency of the protocol for photoactivating PpIX, whereas the effective light dose represents the accumulation of this overall efficiency over the irradiation time. As the damage induced by PDT depends on the amount of singlet oxygen generated per unit volume of tissue during treatment $[53,54]$, local damage appears to be a suitable metric for protocol assessment. Defined as the integration of a function of both the spectral irradiance and the absorption spectrum of PpIX over the irradiation time [7-9], the local damage is computed by mathematical modeling for PDT of AK. This modeling takes into account the spatial and temporal variations in the absorption spectrum of PpIX during treatment: the absorption spectrum of PpIX is initialized depending on the incubation time and then changes in space and time along the irradiation time according to the biological clearance of PpIX, the conversion of MAL to PpIX and the photobleaching of PpIX. All protocol information is integrated in the local damage computation.

All five metrics are computed using a Matlab ${ }^{\mathrm{TM}}$ program on a standard personal computer (Intel Xeon CPU E5-2660 V3 - 2.60 GHz - 64 GB of RAM - Windows 764 bits). Based on their greater relevance for evaluating protocols for PDT of AK, only the effective irradiance, the effective light dose and the local damage are used as comparative metrics. Both the effective light dose and the local damage are quantities that accumulate over the irradiation time and could therefore be predictors of clinical outcome. For this reason, we also investigate whether there is an association between the clinical outcome - which is available in terms of the complete response rate at three months for nine of the ten protocols - and the effective light dose or local damage. 
Table 1: The ten ALA- and MAL-PDT protocols investigated in this study: characteristics (columns 2 to 6), complete response rates at three months (column 7) and pain scores during irradiation (column 8). Both the complete response rates at three months and pain scores during irradiation considered in this study are derived from the literature and were achieved in AK after one PDT session.

\begin{tabular}{|c|c|c|c|c|c|c|c|}
\hline & $\begin{array}{c}\text { Incubation time } \\
\text { (Photosensitizing } \\
\text { cream) }\end{array}$ & $\begin{array}{l}\text { Should the excess } \\
\text { photosensitizing } \\
\text { cream be removed } \\
\text { (Any potential } \\
\text { additional } \\
\text { information) }\end{array}$ & $\begin{array}{l}\text { Irradiation } \\
\text { time }\end{array}$ & Irradiance & $\begin{array}{l}\text { Light } \\
\text { dose }\end{array}$ & $\begin{array}{l}\text { AK complete response } \\
\text { rates at three months }\end{array}$ & $\begin{array}{l}\text { Pain scores } \\
\text { ranging from } 0 \\
\text { (no pain) to } 10 \\
\text { (maximum } \\
\text { pain) }\end{array}$ \\
\hline PDT protocol for & 3 hours (MAL) & Yes & 487 & 154 & 75 & - $68 \%$ (This & \\
\hline
\end{tabular}




\begin{tabular}{|c|c|c|c|c|c|c|c|}
\hline $\begin{array}{c}\text { the CureLight } 01 \\
\text { lamp [23-26] }\end{array}$ & & & seconds & $\begin{array}{c}\mathrm{mW} / \mathrm{cm}^{2} \\
{[23]}\end{array}$ & $\mathrm{J} / \mathrm{cm}^{2}$ & $\begin{array}{l}\text { percentage is } \\
\text { related to facial } \\
\text { and scalp AK, for } \\
\text { which only one } \\
\text { PDT session was } \\
\text { performed) [26] }\end{array}$ & \\
\hline $\begin{array}{l}\text { PDT protocol for } \\
\text { the Blu-U } \\
\text { illuminator [36- } \\
\text { 39] }\end{array}$ & 14 hours (ALA) & Yes & $\begin{array}{c}1000 \\
\text { seconds }\end{array}$ & $\begin{array}{c}10 \\
\mathrm{~mW} / \mathrm{cm}^{2}\end{array}$ & $\begin{array}{c}10 \\
\mathrm{~J} / \mathrm{cm}^{2}\end{array}$ & - $86 \%$ [39] & \\
\hline $\begin{array}{c}\text { Protocol for the } \\
\text { Omnilux PDT тм } \\
\text { [28] }\end{array}$ & 4 hours (ALA) & Yes & $\begin{array}{l}\sim 672.2 \\
\text { seconds }\end{array}$ & & $\begin{array}{c}40 \\
\mathrm{~J} / \mathrm{cm}^{2}\end{array}$ & - $55.8 \%$ [28] & - 6.95 [28] \\
\hline
\end{tabular}




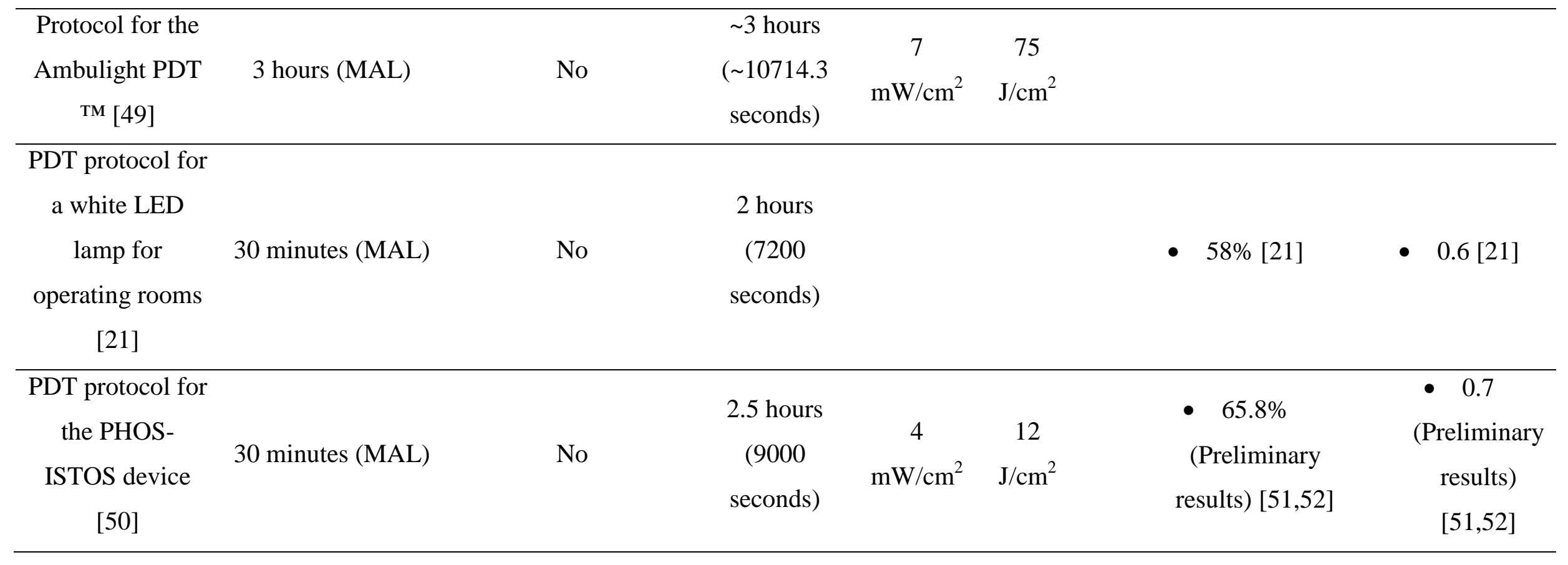




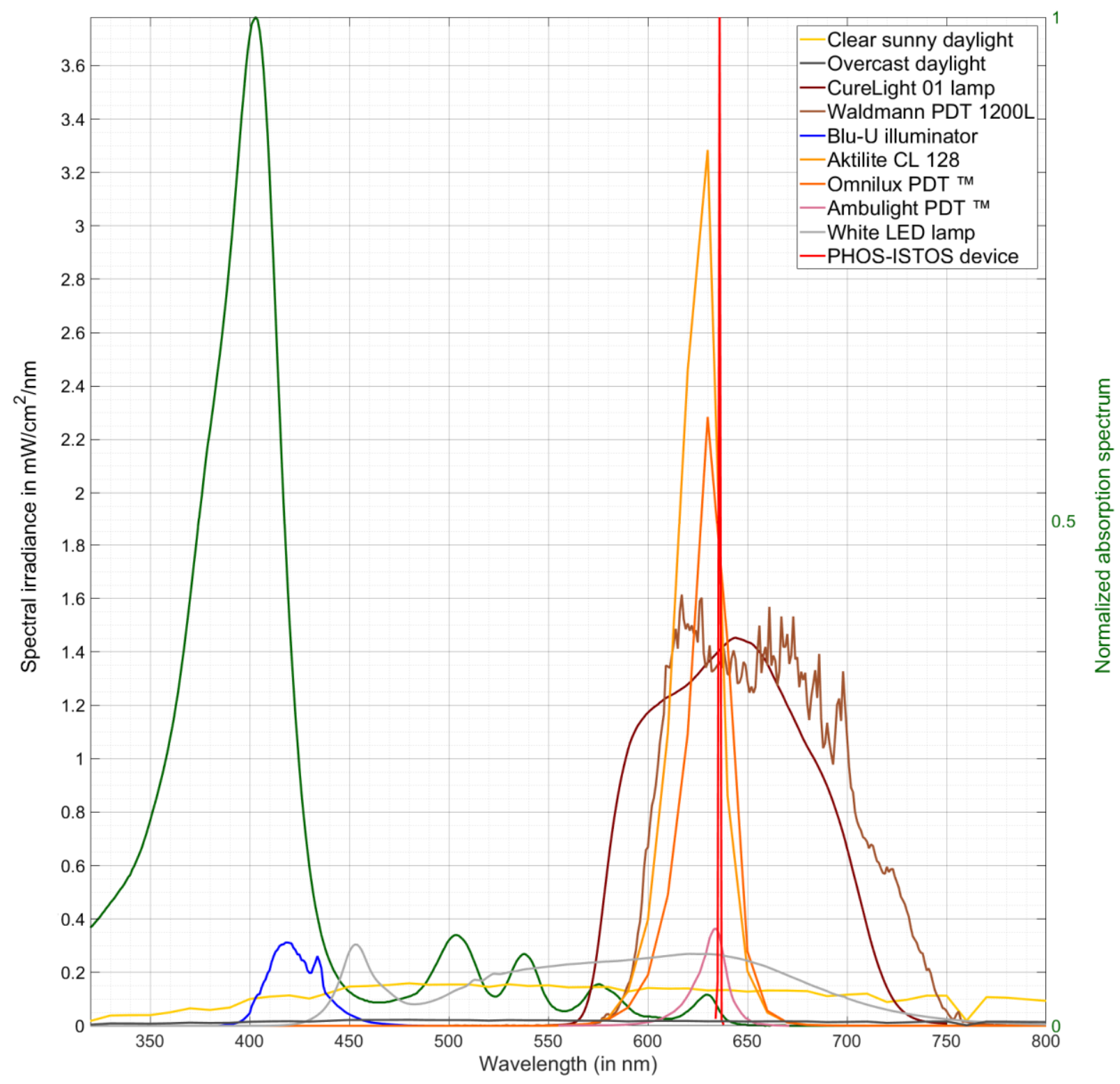

Figure 1: The spectral irradiances for the ten ALA- and MAL-PDT protocols investigated in this study are scaled according to the left axis; the normalized absorption spectrum for PpIX (green curve) is plotted according to the right axis.

\section{Results}

Figure 2 allows a comparison of the ten ALA- and MAL-PDT protocols investigated in this study in terms of effective irradiance, effective light dose and local damage, all the three computed from the protocols information reported in Table 1 and Figure 1. 
Table 2: Effective irradiances, effective light doses, local damage and other quantitative criteria computed from the spectral irradiances for the ten ALA- and MAL-PDT protocols investigated in this study.

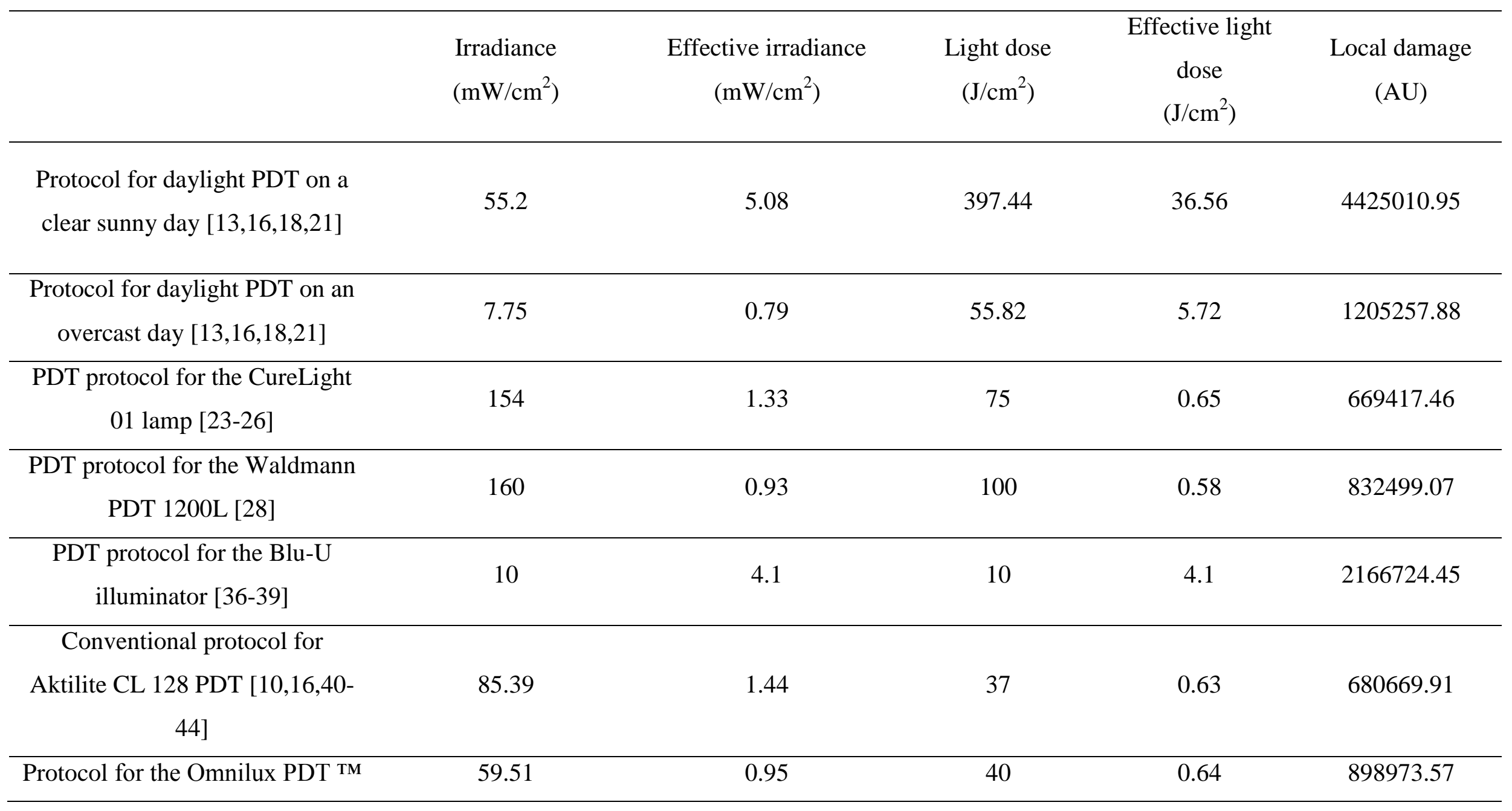




$$
\text { [28] }
$$

\begin{tabular}{ccccc}
\hline $\begin{array}{c}\text { Protocol for the Ambulight PDT } \\
\text { TM [49] }\end{array}$ & 7 & 0.12 & 75 & 1.32 \\
\hline $\begin{array}{l}\text { PDT protocol for a white LED } \\
\text { lamp for operating rooms [21] }\end{array}$ & 56.05 & 1.35 & 403.58 & 9.73 \\
\hline $\begin{array}{c}\text { PDT protocol for the PHOS- } \\
\text { ISTOS device [50] }\end{array}$ & 4 & 0.06 & 12 & 0.18 \\
\hline
\end{tabular}




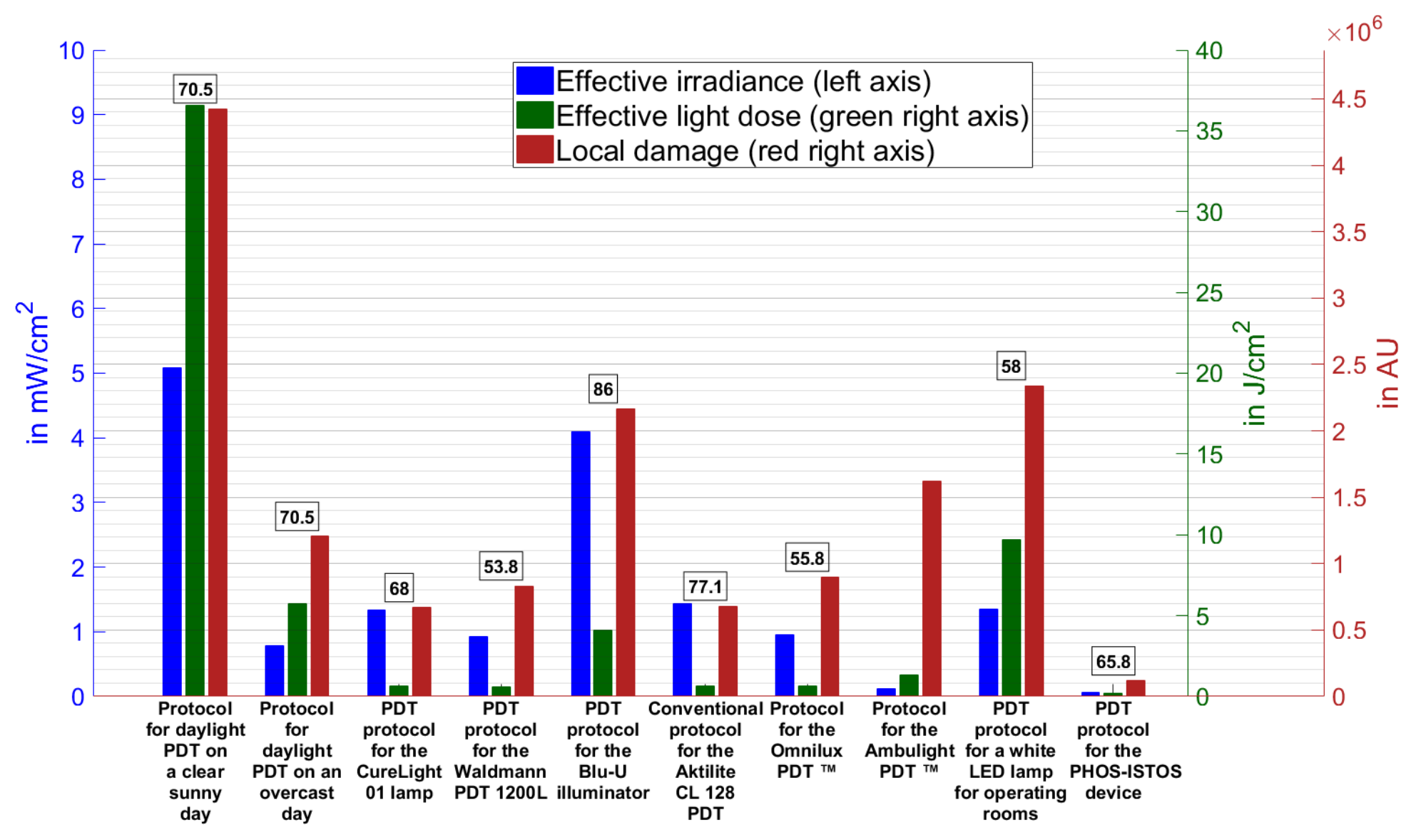

Figure 2: Representation of the effective irradiances (blue bars), effective light doses (green bars) and local damage (red bars) for the ten ALAand MAL-PDT protocols investigated in this study. For each protocol, the average complete response rate at three months, computed from the values reported in column 7 in Table 1, is specified in the text box above the bars related to the protocol. 
Table 2 (column 3) and Figure 2 (blue bars) indicate a wide range of effective irradiances, from $0.06 \mathrm{~mW} / \mathrm{cm}^{2}$ for the PDT protocol for the PHOS-ISTOS device to $5.08 \mathrm{~mW} / \mathrm{cm}^{2}$ for the protocol for daylight PDT on a clear sunny day. This wide range results from the variations in position, shape and amplitude of the spectral irradiances with regard to the normalized absorption spectrum for PpIX (Figure 1).

With a spectral irradiance completely overlapping the normalized absorption spectrum of PpIX and an irradiance of $55.2 \mathrm{~mW} / \mathrm{cm}^{2}$, the protocol for daylight PDT on a clear sunny day provides the highest effective irradiance and therefore is the most efficient protocol for photoactivating PpIX. The protocol for daylight PDT on an overcast day, which involves a spectral irradiance with substantially the same broadband shape but an amplitude approximately seven times lower than that of the protocol for daylight PDT on a clear sunny day, is the eighth most efficient protocol for photoactivating PpIX. In spite of a partial overlap of the spectral irradiance with the first peak in the normalized absorption spectrum for PpIX, which is the most effective peak for photoactivation of PpIX (wavelength range of $300 \mathrm{~nm}$ to $460 \mathrm{~nm}$ in Figure 1), the PDT protocol for the Blu-U illuminator only provides the second highest effective irradiance. This result occurs because the irradiance of $10 \mathrm{~mW} / \mathrm{cm}^{2}$ for the PDT protocol for the Blu-U illuminator is more than five times lower than that for the protocol for daylight PDT on a clear sunny day. Although large differences exist in their spectral irradiances (Figure 1), the conventional protocol for Aktilite CL 128 PDT, the PDT protocol for a white LED lamp for operating rooms and the PDT protocol for the CureLight 01 lamp provide quite similar effective irradiances, ranked as the third, fourth and fifth highest effective irradiance, respectively. The ranks of the conventional protocol for Aktilite CL 128 PDT and the PDT protocol for the CureLight 01 result from the high irradiances of $85.39 \mathrm{~mW} / \mathrm{cm}^{2}$ and $154 \mathrm{~mW} / \mathrm{cm}^{2}$, which partially offset the overlap of the spectral irradiances with the two least effective peaks for photoactivation of PpIX in the normalized absorption spectrum for PpIX. The fourth rank of the PDT protocol for a white LED lamp for operating rooms is based on the combination of a suitable irradiance and the complete overlap of the spectral irradiance with the normalized absorption spectrum of PpIX. With substantially the same shape but an amplitude lower than that for the conventional protocol for Aktilite CL 128 PDT, the spectral irradiance for the protocol for the Omnilux PDT тм leads to the sixth highest effective irradiance. The irradiance of the PDT protocol for the Waldmann PDT $1200 \mathrm{~L}$, although the highest in this study, does not compensate for the approximately $50 \%$ of the spectral irradiance that matches the wavelength range of $650 \mathrm{~nm}$ to $800 \mathrm{~nm}$ and therefore does not contribute to the photoactivation of PpIX. This non-contribution, which might 
introduce unwanted heating of the tissue by infrared absorption and which is also observed for the PDT protocol for the CureLight 01 lamp, is clearly identifiable in Figure 1. With the two lowest irradiances in this study and an overlap of their spectral irradiances with the fifth absorption peak in the normalized absorption spectrum for PpIX, the protocol for the Ambulight PDT тм and the PDT protocol for the PHOS-ISTOS device are the two least efficient protocols for photoactivating PpIX.

The effective light dose, which is computed by integrating the effective irradiance over the irradiation time (column 4 in Table 1), also varies considerably in amplitude (column 5 in Table 2, green bars in Figure 2).

With the highest effective irradiance (previous paragraph) and one of the longest irradiation times, the protocol for daylight PDT on a clear sunny day provides the highest effective light dose (value, $36.56 \mathrm{~J} / \mathrm{cm}^{2}$ ). The PDT protocol for a white LED lamp for operating rooms has the second highest effective light dose due to the combination of the fourth highest effective irradiance with the third longest irradiation time. The protocol for daylight PDT on an overcast day and the PDT protocol for the Blu-U illuminator provide the third and fourth highest effective light doses, respectively. With the longest irradiation time in this study, the protocol for the Ambulight PDT TM moves from ninth place in terms of effective irradiance to fifth place in terms of effective light dose. By contrast, the PDT protocol for the CureLight 01 lamp, the PDT protocol for the Waldmann PDT 1200L, the conventional protocol for Aktilite CL 128 PDT and the protocol for the Omnilux PDT тM, which have the shortest irradiation times in this study, are lower ranked in terms of effective light dose than in terms of effective irradiance. For the PDT protocol for the PHOS-ISTOS device, the irradiation time of 2.5 hours - the second highest irradiation time in this study (column 4 in Table 1) - does not result in better performance in terms of effective light dose (last rank with a value of 0.18 $\mathrm{J} / \mathrm{cm}^{2}$ ) than in terms of effective irradiance. Based on the results reported in columns 4 and 6 of Table 2, all protocols with an irradiation time strictly less than two hours perform lower in terms of effective light dose than in terms of effective irradiance, whereas the other protocols are better or equally ranked in effective light dose compared to effective irradiance.

With respect to local damage (red bars in Figure 2), which is computed by taking into account the time and depth variations of the absorption spectrum for PpIX along the PDT process, the protocol for daylight PDT on a clear sunny day is the most effective protocol in this study. The PDT protocol for a white LED lamp for operating rooms takes second place, followed 
closely by the PDT protocol for the Blu-U illuminator. These results are mainly due to the relevant overlaps of the corresponding spectral irradiances with the normalized absorption spectrum of PpIX. Due to their long irradiation times, the protocol for the Ambulight PDT TM and the protocol for daylight PDT on an overcast day provide the fourth and fifth highest local damage, respectively. Next, the PDT protocol for the CureLight 01 lamp, the PDT protocol for the Waldmann PDT 1200L, the conventional protocol for Aktilite CL 128 PDT and the protocol for the Omnilux PDT TM achieve relatively similar levels of local damage, while the lowest local damage is achieved by the PDT protocol for the PHOS-ISTOS device.

The rankings of the protocol for daylight PDT on a clear sunny day, the conventional protocol for Aktilite CL 128 PDT, the PDT protocol for a white LED lamp for operating rooms and the PDT protocol for the PHOS-ISTOS device based on local damage are identical to those based on effective light dose. For the other protocols, the rankings in terms of local damage are only slightly different from that based on effective light dose. These differences are partly due to the implicit consideration of the incubation time in the local damage calculation, i.e., the initialization of the absorption spectrum of PpIX depending on the incubation time. As a result, six of the seven protocols involving an incubation time less than or equal to three hours are equally or lower ranked in local damage than in effective light dose, whereas the three protocols involving an incubation time longer than four hours perform better in terms of local damage than in terms of effective light dose.

As shown in Figure 2, the average complete response rate at three months (text boxes) does not appear to depend on either the effective light dose or the local damage. With the two highest effective light doses and the two highest local damages, the protocol for daylight PDT on a clear sunny day and the PDT protocol for a white LED lamp for operating rooms achieve average complete response rates at three months of $70.5 \%$ and $58 \%$, respectively. These values are smaller than those achieved using the PDT protocol for the Blu-U illuminator (86\%) and the conventional protocol for Aktilite CL 128 PDT (77.1\%), which both provide lower light doses and lower local damage.

Figures 3 and 4, which show the complete response rates at three months versus the effective light dose and the complete response rates at three months versus the local damage, support this assumption of no dependence. In fact, based on the near-zero slopes of the regression 
lines (green curves in Figures 3 and 4), there are no associations of the complete response rate at three months with the effective light dose and local damage. 


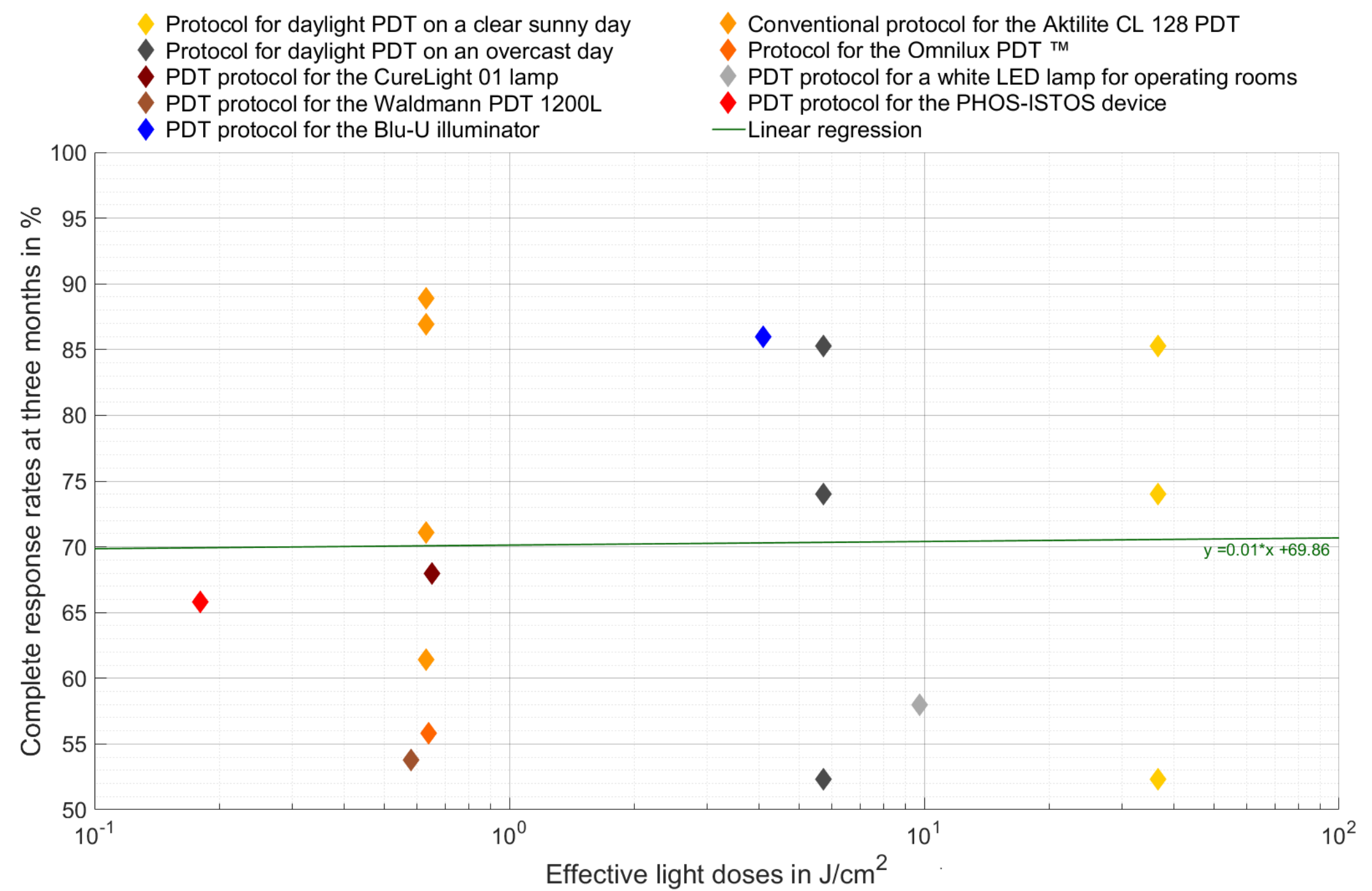

Figure 3: The complete response rates at three months reported in AK after one PDT session (column 8 in Table 1) versus the effective light dose (green bars in Figure 2). 


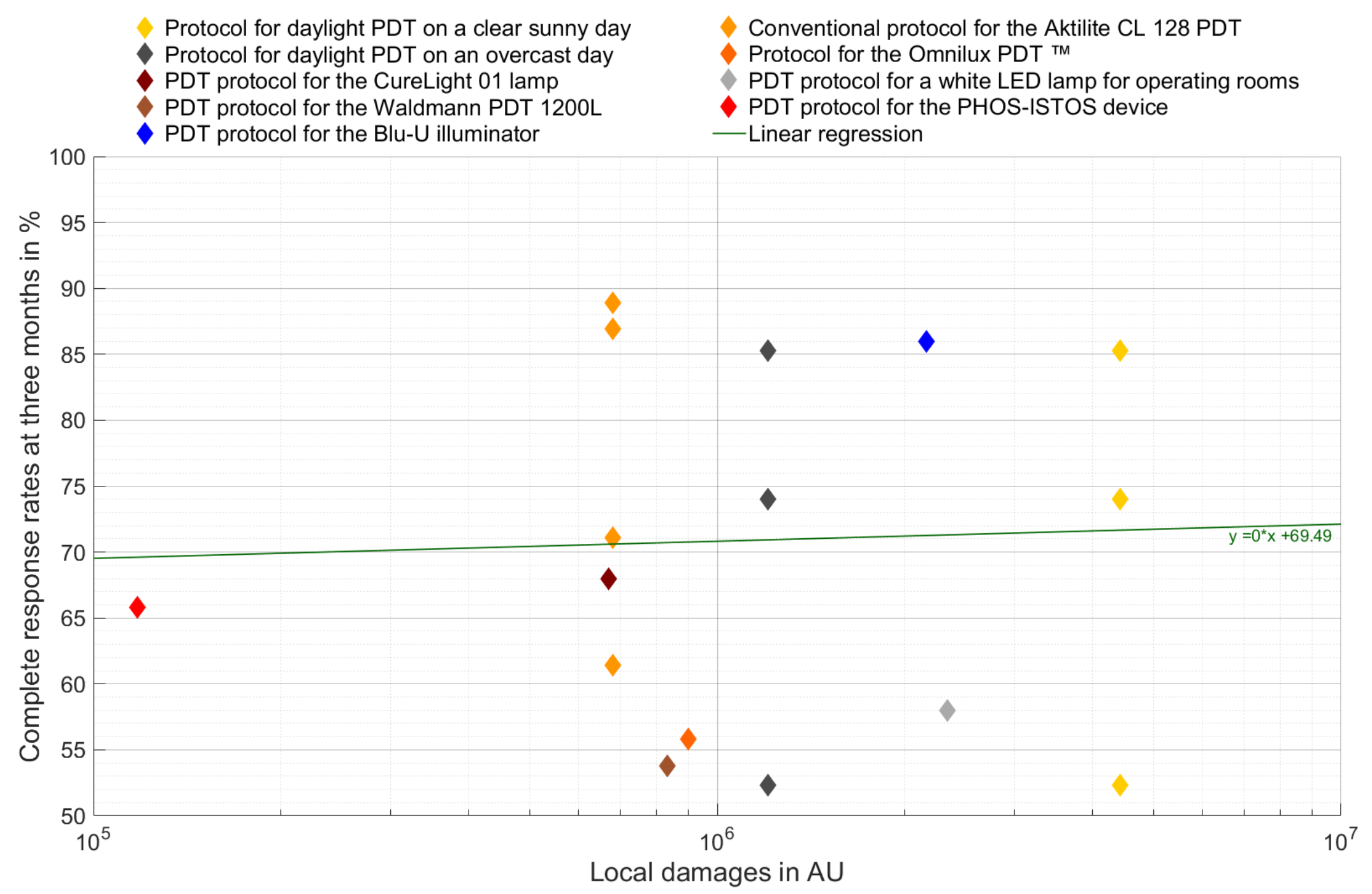

Figure 4: The complete response rates at three months reported in AK after one PDT session (column 8 in Table 1) versus the local damage (red bars in Figure 2). 


\section{Discussion}

In this paper, ten ALA- and MAL-PDT protocols for PDT of AK are evaluated and compared using three metrics: the effective irradiance, the effective light dose and local damage.

These protocols, which include protocols approved in Europe and the United States for treating AK (Table 1), were chosen based on the availability of spectral data necessary to compute the comparative metrics and for their published clinical efficacy.

The effective irradiance obtained from the integration over the wavelength of the spectral irradiance weighted by the normalized absorption spectrum of PpIX (green curve in Figure 1) indicates the overall efficiency of the protocol for photoactivating PpIX. As described in the Results section, due to the position, shape and amplitude of the spectral irradiances, the protocol for daylight PDT on a clear sunny day and the PDT protocol for the Blu-U illuminator are the two most efficient protocols for photoactivating PpIX. By contrast, the protocol for the Ambulight PDT TM and the PDT protocol for the PHOS-ISTOS device are the two least efficient protocols for photoactivating PpIX. The six remaining protocols are roughly equivalent to each other in terms of efficiency of photoactivation of PpIX.

The effective light dose is obtained from the integration of the effective irradiance over the irradiation time and therefore represents the accumulation of the overall efficiency of the protocol for photoactivating PpIX over the irradiation time. As shown in Figure 2, the protocol for daylight PDT on a clear sunny day provides the highest effective light dose, $36.56 \mathrm{~J} / \mathrm{cm}^{2}$, approximately 3.8 times higher than the effective light doses achieved by the other investigated protocols. The protocols providing the four highest effective light doses are the protocols involving irradiation with daylight, white light or blue light, whereas the effective light doses for the protocols involving red light irradiation are much lower. These differences are explained by the generally much shorter irradiation times and poorer overlap with the normalized absorption spectrum of PpIX of the protocols involving red light irradiation compared to the other protocols, i.e., long wavelengths are characterized by low photo-activation intensities of PpIX (Table 1, Figure 1). 
The local damage refers to the number of singlet oxygen molecules generated during the treatment in a $5 \mu \mathrm{m} \times 5 \mu \mathrm{m} \times 5 \mu \mathrm{m}$ volume located at a depth of $100 \mu \mathrm{m}$ in AK. This depth was chosen based on the 100- $\mu \mathrm{m}$ thickness for the epidermis reported in [55] and on the confinement of the AK to the epidermis. This number was estimated using an original mathematical model for PDT of AK that we published previously [7-9]. As shown in Figure 2 , four of the five highest levels of local damage are provided by the protocols involving irradiation with daylight, white light or blue light. With the exception of the protocol for the Ambulight PDT TM, the protocols involving red light irradiation, particularly the PDT protocol for the PHOS-ISTOS device, are the least efficient protocols in terms of local damage. Similar to the effective light dose, this result can be explained by the short irradiation times and the poor overlap with the normalized absorption spectrum of PpIX associated with these protocols.

As discussed above, the protocols involving red light irradiation perform lower than the other protocols in terms of both the effective light dose and local damage.

With regard to local damage, the $100-\mu \mathrm{m}$ depth does not appear to be sufficient to highlight the deeper tissue penetration of red light compared to light of shorter wavelengths and to offset the poor overlap of the corresponding spectral irradiances with the normalized absorption spectrum of PpIX. Further studies involving a greater depth would be interesting to assess the impact of the deep tissue penetration of red light.

In contrast to the effective light dose, local damage is computed by taking into account the spatial and temporal variations of the absorption spectrum of PpIX during irradiation. This distinction results in some slight differences in the rankings based on effective light dose and local damage. These differences can be explained in part by the incubation time, from which the absorption spectrum of PpIX is initialized. All four protocols involving an incubation time longer than four hours perform better in terms of effective light dose than in terms of local damage. The effective light dose therefore could be improved by including the incubation time in its calculation.

Defined as quantities accumulating over the irradiation time, the effective light dose and local damage were expected to provide relevant trends for clinical efficacy. The complete response rate at three months, which was available for nine of the ten investigated protocols, was used to assess this clinical efficacy. As shown in Figures 3 and 4, there are no associations of the 
complete response rate at three months with the effective light dose or local damage. Indeed, higher effective light doses or greater local damage does not always lead to higher complete response rates at three months. The effective light dose and local damage therefore cannot be used to determine the most efficient protocol in terms of the complete response rate at three months.

This result could reflect the potential overtreatment of $\mathrm{AK}$ when using all protocols investigated in this study. This overtreatment would lead to effective light doses and local damage levels that are higher than the threshold values for PDT treatment success. Further investigations could be performed to determine whether such threshold values can be established. These investigations would extend the comparison to more protocols for PDT of AK, subject to published clinical efficacy and available spectral irradiance for the light source. Some emerging protocols aimed at allowing indoor daylight PDT [56] or maintaining pain control during the treatment [57] could be considered. However, this assumption of overtreatment should be further discussed as the complete response rates at three months were from different studies, and therefore their comparison is not fully reliable due to the variability across studies.

Another hypothesis for explaining this result is potential deviations from the reported protocol information from which the effective light doses and local damage were computed. Information such as incubation time or irradiation time may not always be respected when treating patients, leading to biased complete response rates at three months.

Given a protocol, the varying distances between the lesions and the light source result in interpatient/inter-lesion variability in the spectral irradiance. This variability is implicitly included in the complete response rate at three months but is not reflected by either the effective light dose or the local damage. This may also explain the absence of associations of the complete response rate at three months with the effective light dose or local damage.

Regarding the local damage computation, the absorption spectrum of PpIX is initialized depending on the incubation time [7-9] and does not take into account the inter-patient/interlesion variability in the conversion of MAL to PpIX. By contrast, the complete response rate at three months is intrinsically linked to this variability, which represents a source of bias in the comparisons of the complete response rate at three months with the effective light dose or local damage. 
A limited, inaccurate, or incomplete understanding of the PDT process could also lead to biased local damage and potentially to the absence of associations between local damage and the complete response rate at three months.

Consideration also needs to be given to the treatment-associated pain. With pain scores ranging from 0.4 to 1.9 (column 8 in Table 1), the protocol for daylight PDT, regardless of weather conditions, is described as a nearly painless treatment $[16,18,21]$. This description, which is also reported for the PDT protocol for a white LED lamp for operating rooms (pain score: 0.6), is applicable to the PDT protocol for the PHOS-ISTOS device (pain score: 0.6). Based on the pain score of 2 reported by Ibbotson et al [49] for the treatment of 61 nonmelanoma skin lesions, including only one AK, the protocol for the Ambulight PDT TM involves little pain. By contrast, three of the protocols involving red light irradiation (the PDT protocol for the Waldmann PDT 1200L, the conventional protocol for Aktilite CL 128 PDT and the protocol for the Omnilux PDT TM) have pain scores higher than 5, indicating that these protocols are very painful. Severe pain and burning sensation of the skin, which may lead to interruption of treatment, have also commonly been reported for the PDT protocol for the CureLight 01 lamp [23,24,26] and for the PDT protocol for the Blu-U illuminator [38,39]. The protocols involving irradiation with daylight or white light and the protocols involving red light and low effective irradiances therefore seem to be more convenient for patients.

Moreover, no associations seem to exist between the above-mentioned pain scores and adverse effects and the effective light doses or local damage.

Since no single study provides complete response rates and pain scores for all ten protocols, data from various studies had to be pooled. To reduce variability across studies, only studies reporting complete response rates and pain scores achieved in AK after one PDT session are considered in the present study. Although reduced, variability still exists across studies, leading to limited reliability of the comparisons of complete response rates and pain scores. This constitutes a limitation of the study. To make the comparisons fully reliable, a single clinical study comparing the ten protocols should be conducted.

Based on the above-discussed absence of an association between the effective light dose or local damage and the complete response rate at three months, protocols achieving high complete response rates at three months and low pain scores should be preferred, i.e., the 
protocol for daylight PDT, regardless of weather conditions, and the PDT protocol for the PHOS-ISTOS device.

\section{Conclusions}

In this paper, we have compared ten efficient protocols for PDT of AK. This comparison in terms of effective irradiance, effective light dose and local damage demonstrates that the protocol for daylight PDT, regardless of weather conditions, the PDT protocol for a white LED lamp for operating rooms and the PDT protocol for the Blu-U illuminator perform better than the six other protocols, all of which involve red light illumination. However, no association between the effective light dose or local damage and the complete response rate at three months could be established. The protocol decision should therefore be determined based on the complete response rates and, in case of similar response rates, the pain scores. Based on the reported complete response rates at three months and pain scores, the protocol for daylight PDT, regardless of weather conditions, and the PDT protocol for the PHOSISTOS device should be preferred.

\section{Acknowledgments}

The authors thank M. Manley from the Department of Medical Physics and Clinical Engineering, Saint Vincent's University Hospital, Dublin, Ireland, UK, for providing the spectral irradiances for several of the protocols investigated in this study.

The authors thank A. Juzeniene from the Department of Radiation Biology, the Norwegian Radium Hospital, Oslo, Norway, for providing the CureLight 01 lamp spectral irradiance. 


\section{Reference List}

1 Plaetzer K., Krammer B., Berlanda J., Berr F., and Kiesslich T., Photophysics and photochemistry of photodynamic therapy: fundamental aspects., Lasers Med Sci., 24, 2, 259 , 268, 2009.

2 Braathen LR., Szeimies RM., Basset-Seguin N., Bissonette R., Foley P., Pariser D., Roelandts R., Wennberg AM., and Morton CA., Guidelines on the use of photodynamic therapy for nonmelanoma skin cancer: an international consensus., J Am Acad Dermatol., 56, 1, 125, 143, 2007.

3 Ericson MB., Wennberg AM., and Larko O, Review of photodynamic therapy in actinic keratosis and basal cell carcinoma., Ther Clin Risk Manag., 4, 1, 1, 9, 2008.

4 Morton CA., McKenna KE., and Rhodes LE., Guidelines for topical photodynamic therapy: update., Br J Dermatol., 159, 6, 1245, 1266, 2008.

5 Morton C., Szeimies RM., Sidoroff A., Wennberg AM., Basset-Seguin N., Calzavara-Pinton P., Gilaberte Y., Hofbauer G., Hunger R., Karrer S., Lehmann P., Piaserico S., Ulrich C., and Braathen L., European Dermatology Forum Guidelines on topical photodynamic therapy., Eur J Dermatol., 25, 4, 296, 311, 2015.

6 Wiegell SR., Update on photodynamic treatment for actinic keratosis., Curr Probl Dermatol., 46, 122, 128, 2015.

7 Vignion-Dewalle AS., Betrouni N., Tylcz JB., Vermandel M., Mortier L., and Mordon S., Comparison of three light doses in the photodynamic treatment of actinic keratosis using mathematical modeling., J Biomed Opt., 20, 5, 58001, 2015.

8 Vignion-Dewalle AS., Baert G., Devos L., Thecua E., Vicentini C., Mortier L., and Mordon S., Red light photodynamic therapy for actinic keratosis using $37 \mathrm{~J} / \mathrm{cm}^{2}$ : fractionated irradiation with $12.3 \mathrm{~mW} / \mathrm{cm}^{2}$ after 30 minutes incubation time compared to standard continuous irradiation with $75 \mathrm{~mW} / \mathrm{cm}^{2}$ after three hours incubation time using a mathematical modeling., Lasers in Surgery and Medicine, 49, 7, 686, 697, 2017.

9 Vignion-Dewalle AS., Baert G., Thecua E., Vicentini C., Mortier L., and Mordon S., Photodynamic therapy for actinic keratosis: European consensus protocol for daylight PDT versus conventional protocol for Aktilite CL 128 PDT using a mathematical modeling., Journal of Photochemistry and Photobiology B: Biology, 174, 70, 77, 2017.

10 Wiegell SR., Haedersdal M., Philipsen PA., Eriksen P., Enk CD., and Wulf HC., Continuous activation of PpIX by daylight is as effective as and less painful than conventional photodynamic therapy for actinic keratoses; a randomized, controlled, single-blinded study., Br J Dermatol., 158, 4, 740, 746, 2008.

11 Wiegell SR., Haedersdal M., Eriksen P., and Wulf HC., Photodynamic therapy of actinic keratoses with $8 \%$ and $16 \%$ methyl aminolaevulinate and home-based daylight exposure: a double-blinded randomized clinical trial., Br J Dermatol., 160, 6, 1308, 1314, 2009.

12 Wiegell SR., Fabricius S., Stender IM., Berne B., Kroon S., Andersen BL., Mork C., Sandberg C, Jemec GB., Mogensen M., Brocks KM., Philipsen PA., Heydenreich J., Haedersdal M., and Wulf HC., A randomized, multicentre study of directed daylight exposure times of $1 \frac{1}{2}$ vs. $2 \frac{1}{2}$ 
$\mathrm{h}$ in daylight-mediated photodynamic therapy with methyl aminolaevulinate in patients with multiple thin actinic keratoses of the face and scalp., Br J Dermatol., 164, 5, 1083, 1090, 2011.

13 Wiegell SR., Wulf HC., Szeimies RM., Basset-Seguin N., Bissonette R., Gerritsen MJ., Gilaberte Y., Calzavara-Pinton P., Morton CA., Sidoroff A., and Braathen LR., Daylight photodynamic therapy for actinic keratosis: an international consensus: International Society for Photodynamic Therapy in Dermatology., J Eur Acad Dermatol Venereol., 26, 6, 673, 679, 2012.

14 Wiegell SR., Fabricius S., Gniadecka M., Stender IM., Berne B., Kroon S., Andersen BL., Mork C., Sandberg C, Ibler KS., Jemec GB., Brocks KM., Philipsen PA., Heydenreich J., Haedersdal M., and Wulf HC., Daylight-mediated photodynamic therapy of moderate to thick actinic keratoses of the face and scalp: a randomized multicentre study., Br J Dermatol., 166, 6, 1327, 1332, 2012.

15 Wiegell SR., Fabricius S., Heydenreich J., Enk CD., Rosso S., Bäumler W., Baldursson BT., and Wulf HC., Weather conditions and daylight-mediated photodynamic therapy: protoporphyrin IX-weighted daylight doses measured in six geographical locations., $\mathrm{Br} \mathrm{J}$ Dermatol., 168, 1, 186, 191, 2013.

16 Rubel DM., Spelman L., Murrell DF., See JA., Hewitt D., Foley P., Bosc C., Kerob D., Kerrouche N., Wulf HC., and Shumack S., Daylight photodynamic therapy with methyl aminolevulinate cream as a convenient, similarly effective, nearly painless alternative to conventional photodynamic therapy in actinic keratosis treatment: a randomized controlled trial., Br J Dermatol., 171, 5, 1164, 1171, 2014.

17 Perez-Perez L., Garcia-Gavin J., and Gilaberte Y., Daylight-mediated photodynamic therapy in Spain: advantages and disadvantages., Actas Dermosifiliogr., 105, 7, 663, 674, 2014.

18 Neittaanmäki-Perttu N., Karppinen TT., Grönroos M., Tani TT., and Snellman E., Daylight photodynamic therapy for actinic keratoses: a randomized double-blinded nonsponsored prospective study comparing 5-aminolaevulinic acid nanoemulsion (BF-200) with methyl-5aminolaevulinate., British Journal Of Dermatology, 171, 5, 1172, 1180, 2014.

19 Lane KL., Hovenic W., Ball K., and Zachary CB., Daylight photodynamic therapy: the Southern California experience., Lasers Surg Med., 47, 2, 168, 172, 2015.

20 Spelman L., Rubel D., Murrell DF., See JA., Hewitt D., Foley P., Salmon R., Kerob D., Pascual T., Shumack S., and Fernandez-Penas P., Treatment of face and scalp solar (actinic) keratosis with daylight-mediated photodynamic therapy is possible throughout the year in Australia: Evidence from a clinical and meteorological study., Australas J Dermatol., 57, 1, 24, 28, 2016.

21 O'Gorman SM., Clowry J., Manley M., McCavana J., Gray L., Kavanagh A., Lally A., and Collins P., Artificial White Light vs Daylight Photodynamic Therapy for Actinic Keratoses: A Randomized Clinical Trial., JAMA Dermatology, 152, 6, 638, 644, 2016.

22 Wulf HC., Photodynamic Therapy in Daylight for Actinic Keratoses., JAMA Dermatol., 152, 6, 631, 632, 2016.

23 Pariser DM., Lowe NJ., Stewart DM., Jarratt MT., Lucky AW., Pariser RJ., and Yamauchi PS., Photodynamic therapy with topical methyl aminolevulinate for actinic keratosis: Results of a prospective randomized multicenter trial., J Am Acad Dermatol., 48, 2, 227, 232, 2003. 
24 Freeman M., Vinciullo C., Francis D., Spelman L., Nguyen R., Fergin P., Thai KE., Murrell D., Weightman W., Anderson C., Reid C., Waton A., and Foley P., A comparison of photodynamic therapy using topical methyl aminolevulinate (Metvix) with single cycle cryotherapy in patients with actinic keratosis: a prospective, randomized study., J Dermatolog Treat., 14, 2, 99, 106, 2003.

25 Braathen LR., Paredes BE., Saksela O., Fritsch C., Gardlo K., Morken T., Frolich KW., Warloe T., Soler AM., and Ros AM., Short incubation with methyl aminolevulinate for photodynamic therapy of actinic keratoses., J Eur Acad Dermatol Venereol., 23, 5, 550, 555, 2009.

26 Szeimies RM., Karrer S., Radakovic-Fijan S., Tanew A., Calzavara-Pinton P., Zane C., Sidoroff A., Hempel M., Ulrich J., Proebstle T., Meffert H., Mulder M., Salomon D., Dittmar HC., Bauer JW., Kernland K., and Braathen L., Photodynamic therapy using topical methyl 5aminolevulinate compared with cryotherapy for actinic keratosis: A prospective, randomized study., J Am Acad Dermatol., 47, 2, 258, 262, 2002.

27 Juzeniene A., Juzenas P., Ma LW., Iani V., and Moan J., Effectiveness of different light sources for 5-aminolevulinic acid photodynamic therapy, Lasers in Medical Science, 19, 3, 139, 149, 2004.

28 Babilas P., Kohl E., Maisch T., Bäcker H., Gross B., Branzan AL., Bäumler W., Landthaler M., Karrer S., and Szeimies RM., In vitro and in vivo comparison of two different light sources for topical photodynamic therapy, British Journal Of Dermatology, 154, 4, 712, 718, 2006.

29 Karrer S., Bäumler W., Abels C., Hohenleutner U., Landthaler M., and Szeimies RM., LongPulse Dye Laser for Photodynamic Therapy: Investigations In Vitro and In Vivo., Lasers in Surgery and Medicine, 25, 1, 51, 59, 1999.

30 Kurwa HA., Yong-Gee SA., Seed PT., Markey AC., and Barlow RJ., A randomized paired comparison of photodynamic therapy and topical 5-fluorouracil in the treatment of actinic keratoses, Journal of the American Academy Of Dermatology, 41, 3, 414, 418, 1999.

31 Varma S., Wilson H., Kurwa HA., Gambles B., Charman C., Pearse AD., Taylor D., and Anstey AV., Bowen's disease, solar keratoses and superficial basal cell carcinomas treated by photodynamic therapy using a large-field incoherent light source., Br J Dermatol., 144, 3, 567, 574, 2001.

32 Clark C., Bryden A., Dawe R., Moseley H., Ferguson J., and Ibbotson H., Topical 5aminolaevulinic acid photodynamic therapy for cutaneous lesions: outcome and comparison of light sources, Photodermatology, Photoimmunology \& Photomedicine, 19, 3, 134, 141, 2003.

33 Sotiriou E., Apalla Z., Chovarda E., Goussi C., Trigoni A., and Ioannides D., Single vs. fractionated photodynamic therapy for face and scalp actinic keratoses: a randomized, intraindividual comparison trial with 12-month follow-up., J Eur Acad Dermatol Venereol., $26,1,36,40,2012$.

34 Giehl KA., Kriz M., Grahovac M., Ruzicka T., and Berking C., A controlled trial of photodynamic therapy of actinic keratosis comparing different red light sources., Eur $\mathbf{J}$ Dermatol., 24, 3, 335, 341, 2014.

35 Steinbauer JM., Schreml S., Babilas P., Zeman F., Karrer S., Landthaler M., and Szeimies RM., Topical photodynamic therapy with porphyrin precursors - assessment of treatment- 
associated pain in a retrospective study, Photochemical and Photobiological Sciences, 8, 8, 1111, 1116, 2009.

36 Ormrod D. and Jarvis B., Topical aminolevulinic acid $\mathrm{HCl}$ photodynamic therapy., Am J Clin Dermatol., 1, 2, 133, 139, 2000.

37 Jeffes EW., McCullough JL., Weinstein GD., Kaplan R., Glazer SD., and Taylor JR., Photodynamic therapy of actinic keratoses with topical aminolevulinic acid hydrochloride and fluorescent blue light., J Am Acad Dermatol., 45, 1, 96, 104, 2001.

38 Piacquadio DJ, Chen DM, Farber HF, Fowler JF, Glazer SD, Goodman JJ, Hruza LL, Jeffes EWB, Ling MR, Phillips TJ, Rallis TM, Scher RK, Taylor CR, and Weinstein GD, Photodynamic Therapy With Aminolevulinic Acid Topical Solution and Visible Blue Light in the Treatment of Multiple Actinic Keratoses of the Face and Scalp, Archives of Dermatology, 140, 1, 41, 46, 2004.

39 Tschen EH, Wong DS, Pariser DM, Dunlap FE, Houlihan A, and Ferdon MB, Photodynamic therapy using aminolaevulinic acid for patients with nonhyperkeratotic actinic keratoses of the face and scalp: phase IV multicentre clinical trial with 12-month follow up., British Journal Of Dermatology, 155, 6, 1262, 1269, 2006.

40 Pariser D., Loss R., Jarratt M., Abramovits W., Spencer J., Geronemus R., Bailin P., and Bruce S., Topical methyl-aminolevulinate photodynamic therapy using red light-emitting diode light for treatment of multiple actinic keratoses: A randomized, double-blind, placebocontrolled study., Journal of the American Academy Of Dermatology, 59, 4, 569, 576, 2008.

41 Morton C., Campbell S., Gupta G., Keohane S., Lear J., Zaki I., Walton S., Kerrouche N., Thomas G., and Soto P., Intraindividual, right-left comparison of topical methyl aminolaevulinate-photodynamic therapy and cryotherapy in subjects with actinic keratoses: a multicentre, randomized controlled study., Br J Dermatol., 155, 5, 1029, 1036, 2006.

42 Szeimies RM., Matheson RT., Davis SA., Bhatia AC., Frambach Y., Klövekorn W., Fesq H., Berking C., Reifenberger J., and Thaçi D., Topical methyl aminolevulinate photodynamic therapy using red light-emitting diode light for multiple actinic keratoses: a randomized study., Dermatologic Surgery, 35, 4, 586, 592, 2009.

43 Kim BS., Kim JY., Song CH., Kim HY., Lee WJ., Lee SJ., and Kim DW., Light-emitting diode laser versus pulsed dye laser-assisted photodynamic therapy in the treatment of actinic keratosis and Bowen's disease., Dermatol Surg., 38, 1, 151, 153, 2012.

44 Kessels JP., Nelemans PJ., Mosterd K., Kelleners-Smeets NW., Krekels GA., and Ostertag JU., Laser-mediated Photodynamic Therapy: An Alternative Treatment for Actinic Keratosis?, Acta Derm Venereol., 96, 3, 351, 354, 2016.

45 Calzavara-Pinton PG., Venturini M., Sala R., Capezzerra R., Parrinello G., Specchia C., and Zane C., Methylaminolaevulinate-based photodynamic therapy of Bowen's disease and squamous cell carcinoma., Br J Dermatol., 159, 1, 137, 144, 2008.

46 Szeimies RM., Ibbotson S., Murrell DF., Rubel D., Frambach Y., De Berker D., Dummer R., Kerrouche N., and Villemagne H., A clinical study comparing methyl aminolevulinate photodynamic therapy and surgery in small superficial basal cell carcinoma $(8-20 \mathrm{~mm})$, with a 12-month follow-up., J Eur Acad Dermatol Venereol., 22, 11, 1302, 1311, 2008. 
47 Moseley H., Allen JW., Ibbotson S., Lesar A., McNeill A., Camacho-Lopez MA., Samuel ID., Sibbett W., and Ferguson J., Ambulatory photodynamic therapy: a new concept in delivering photodynamic therapy., Br J Dermatol., 154, 4, 747, 750, 2006.

48 Attili SK., Lesar A., McNeill A., Camacho-Lopez M., Moseley H., Ibbotson H., Samuel ID., and Ferguson J., An open pilot study of ambulatory photodynamic therapy using a wearable low-irradiance organic light-emitting diode light source in the treatment of nonmelanoma skin cancer., British Journal Of Dermatology, 161, 1, 170, 173, 2009.

49 Ibbotson SH. and Ferguson J., Ambulatory photodynamic therapy using low irradiance inorganic light-emitting diodes for the treatment of non-melanoma skin cancer: an open study., Photodermatol Photoimmunol Photomed., 28, 5, 235, 239, 2012.

50 Vicentini C., Abi-Rached H., Thecua E., Deleporte P., Lecomte F., Mortier L., Vignion AS., Szeimies RM., and Mordon S., PHOS-ISTOS: A new solution for photodynamic treatment of actinic keratosis., American Society for Laser Medicine and Surgery Abstracts, Lasers in Surgery and Medicine, 49, S28, 139, 2017.

51 Mordon S., Vicentini C., Thecua E., Deleporte P., Lecomte F., Vignion AS., Szeimies RM., and Mortier L., Light emitting fabrics for PDT - The PHOS-ISTOS study., 17th Annual Congress of the European Society for Photodynamic Therapy (EURO-PDT), Nice, France, 2018.

52 Vicentini C., Abi-Rached H., Thecua E., Deleporte P., Lecomte F., Vignion-Dewalle AS., Mortier L., Szeimies RM., and Mordon S., PHOS-ISTOS clinical trial: a new solution for photodynamic treatment of actinic keratosis without pain., American Society for Laser Medicine and Surgery Abstracts, Lasers in Surgery and Medicine, 50, 28, In press., 2018.

53 Farrell TJ, Hawkes RP, Patterson MS, and Wilson BC, Modeling of photosensitizer fluorescence emission and photobleaching for photodynamic therapy dosimetry, Applied Optics, 37, 31, 7168, 7183, 1998.

54 Valentine RM, Brown CT, Moseley H, Ibbotson S, and Wood K, Monte Carlo modeling of in vivo protoporphyrin IX fluorescence and singlet oxygen production during photodynamic therapy for patients presenting with superficial basal cell carcinomas, Journal of Biomedical Optics, 16, 4, 048002, 2011.

55 Liu B, Farrell TJ, and Patterson MS, A dynamic model for ALA-PDT of skin: simulation of temporal and spatial distributions of ground-state oxygen, photosensitizer and singlet oxygen, Physics in Medicine and Biology, 55, 5912, 5932, 2010.

56 Lerche CM., Heerfordt IM., Heydenreich J., and Wulf HC., Alternatives to Outdoor Daylight Illumination for Photodynamic Therapy-Use of Greenhouses and Artificial Light Sources, International Journal Of Molecular Sciences, 17, 3, 309, 2016.

57 Paragh G. and Zeitouni NC., Two-Step Irradiance Treatment Can Achieve Excellent Pain Control During Red Light 5-Aminolevulinic Acid Photodynamic Therapy for Actinic Keratoses., Photomed Laser Surg., In press, 2017. 